
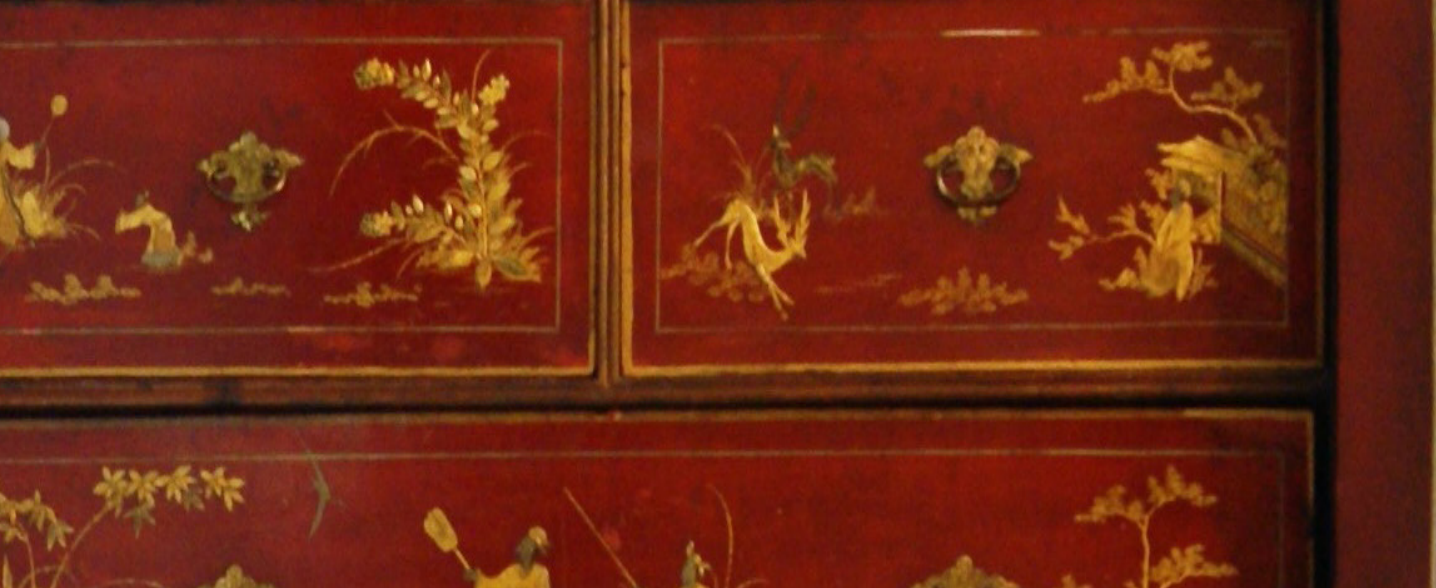

Ge-conservación

Conservação | Conservation

\title{
Análisis estilístico y técnico-científico de un cabinet inédito de laca británica del siglo XVIII, conservado en España
}

\author{
Cristina Ordóñez Goded y Luis Rodrigo Rodríguez Simón
}

Resumen En este artículo se aborda el estudio de un cabinet de laca británica del siglo XVIII que forma parte de una colección privada andaluza, con el propósito de demostrar su posible pertenencia al "Lote de Lazcano", consistente en un emblemático conjunto de muebles que llegó a España entre finales de los años treinta e inicios de los cuarenta del siglo XVIII procedente del taller londinense del famoso ebanista Giles Grendey (1693-1780). Con esta finalidad se han llevado a cabo estudios histórico -artísticos y técnico-científicos para conocer el proceso constructivo y decorativo del referido cabinet. Dichos exámenes se han complementado con un análisis comparativo, tanto técnico como estilístico, con otros ejemplares de la misma tipología, atribuidos a este mismo artífice y conservados en colecciones de distintos países; haciendo hincapié en dos burós de Grendey, custodiados en el Museo Nacional de Artes Decorativas de Madrid.

Palabras clave: cabinet, buró, laca, japanning, Grendey, Lazcano, Museo Nacional de Artes Decorativas, estudios científicos.

\section{A stylistic and technical analysis of an uncataloged british lacquer cabinet from the 18th century and kept in Spain}

Abstract: In this article we will deal with the study of a British lacquer cabinet from the 18th century. It forms part of a private Andalusian collection. The aim of this study is to suggest it may form part of the Lazcano Suite, a collection of pieces of furniture which arrived in Spain in the XVIII century direct from the workshop of the famous cabinet maker Gile Grendey (1693 - 1780). With this aim in mind, stylistic and technical analyses have been performed to pinpoint the technical, structural and ornamental process of this cabinet. These studies are accompanied by a comparative analysis, both stylistic and technical, in the company of similar pieces attributed to the same origin and kept in collections in different countries. Special attention has been paid to two Grendey bookcases kept by the National Museum of Decorative Arts in Madrid.

Keyword: cabinet, bookcase, lacquer, japanning, Grendey, Lazano, National Museum of Decorative Arts in Madrid, scientific studies

\section{Análises estilística e técnica-cientifica de um escritório inédito de laca britânica do século xviii, conservado em Espanha}

Resumo: Neste artigo aborda-se o estudo de um escritório de laca britânica do século XVIII que integra uma coleção privada andaluza, com o propósito de demonstrar a sua possível pertença ao "Lote de Lazcano", consistindo num emblemático conjunto de móveis que chegou a Espanha entre os finais dos anos trinta e inícios dos quarenta do século XVIII, procedente do atelier londrino do famoso ebanista Giles Grendey (1693-1780). Com esta finalidade desenvolveram-se estudos históricos - artísticos e técnicos - e científicos para conhecer o processo construtivo e decorativo do referido escritório. Estes exames foram complementados com uma análise comparativa, tanto técnica como estilística, com outros exemplares da mesma tipologia atribuídos a este mesmo artífice e conservados em coleções de distintos países, com ênfase especial nos escritórios de Grendey, localizados no Museu Nacional de Artes Decorativas de Madrid.

Palavras-chave: cabinet, escritório, laca, japanning, Grendey, Lazcano, Museo Nacional de Artes Decorativas, estudos científicos 


\section{Introducción}

El punto de partida de esta investigación ha sido la realización de un estudio exhaustivo del cabinet ${ }^{[1]}$, [figura 1] que incluye un análisis visual directo, con el propósito de situarlo en un contexto temporal y geográfico concreto.

\section{- Contexto histórico. El "Lote de Lazcano" dentro de las im- portaciones británicas de muebles lacados en España}

El lote de muebles de Lazcano que decoró en su día el palacio homónimo, sito en Guipúzcoa ${ }^{[2]}$, es representativo del tipo de mobiliario de laca británica, más conocida como japanning ${ }^{[3]}$, que se importaba masivamente en nuestro país en el siglo XVIII, dentro de un intenso comercio que involucró a buena parte de artesanos londinenses (Aguiló 2005: 532, 533, Junquera 1999: 434, Symonds 1935: 341, 342, Symonds 1941: 58, 59, Ordóñez 2016: 258- 266, etc.).

De hecho, el japanning era parte integrante del interiorismo español del siglo XVIII, tal y como se refleja en la documentación de este período histórico. Pero además las cédulas de bienes, los almanaques de comercio o la prensa demuestran que la atracción hacia los muebles de laca inglesa se manifestó, tanto entre miembros de la realeza ${ }^{[4]}$, como por parte de nobles y burgueses. Prueba de ello son las reiteradas menciones que encontramos en los inventarios postmortem de personas pertenecientes a ambas categorías sociales (Ordóñez 2016: 266- 280).

Señal del favor que gozó este tipo de mobiliario en España es asimismo el elevado número de ejemplares que aún se conservan en distintas colecciones públicas y privadas españolas, muy superior al procedente de otros países y que constituye una rica parcela de nuestro patrimonio histórico artístico.

Tras lo expuesto es fácil entender la notable influencia que estos muebles ejercieron en los de nuestro país. De ahí que el color rojo, favorito de la laca inglesa, fuera uno de los preferidos por los lacadores españoles. Pero también los prototipos, así como los repertorios decorativos, seguían en gran medida los patrones del japanning.

Los muebles que se importaban en mayor cuantía eran asientos, relojes y burós. Son muchos los historiadores británicos que hacen hincapié en su singularidad, aludiendo a los rasgos que los distinguían de aquellos elaborados para el mercado interior y cuyo estilo se adaptaba hipotéticamente a los gustos de la clientela española y a las características de nuestro clima, utilizando para ello, a menudo, argumentos hiperbólicos y muy alejados de la realidad hispana del siglo XVIII (Symonds 1941:59, Symonds 1986: 81, Remington 1937: 210 ${ }^{[5]}$.

Como se ha dicho, los muebles realizados por Giles Grendey ${ }^{[6]}$ para Lazcano constituyen un botón de muestra del estilo de japanning que se importaba masivamente en nuestro

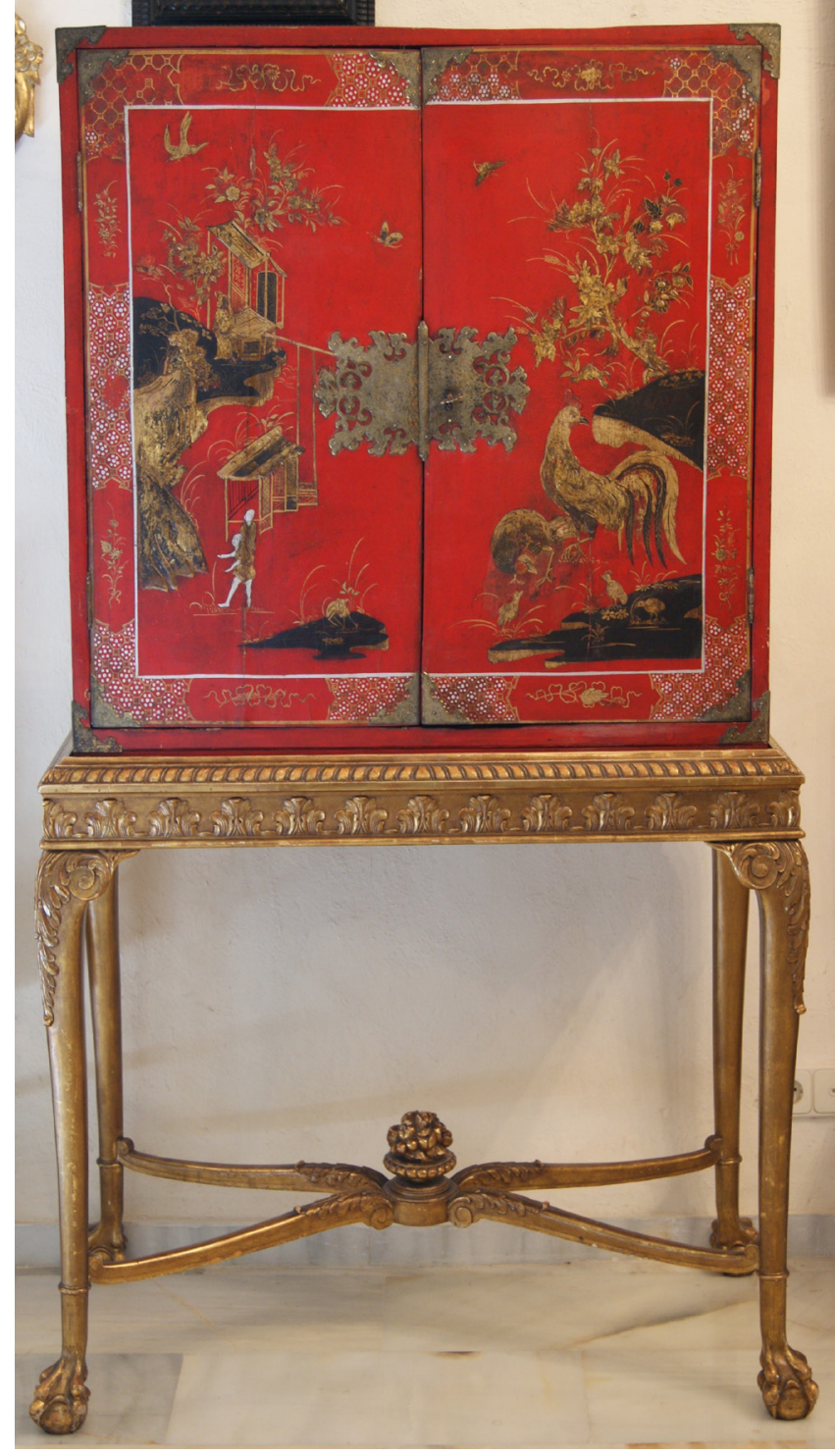

Figura 1.- Vista frontal del cabinet de colección particular andaluza, con las puertas cerradas y apoyado sobre una mesa de madera tallada y dorada con patas cabriolé y chambranas en forma de X. Muestra una ornamentación de laca roja con chinerías perfiladas en negro y guarniciones de metal, dorado y grabado, en las cantoneras de las puertas y en los herrajes de la cerradura.

país en el siglo XVIII, haciendo las delicias de una refinada clientela española y que formaba parte integrante de los ambientes más exquisitos y "a la moda". Estas obras se conservaron en el Palacio de Lazcano hasta 1930. De hecho, existe una foto tomada a finales del siglo XIX o inicios del XX de un salón del palacio, conocido como "salón de las lacas" (Arteaga 1944: 433), donde se pueden apreciar las piezas que formaron parte del mismo.

En la fecha mencionada el anticuario alemán Adolph Loewi (1888-1977) compró la mayor parte de los muebles de Grendey existentes en Lazcano ${ }^{[7]}$. Desde entonces se dispersaron por diferentes países y en la actualidad muchos de ellos se custodian en distintos museos de Europa, 
América y Australia ${ }^{[8]}$. También se han localizado piezas del lote en el comercio de antigüedades (Ordóñez 2011: 17, 18).

El conjunto de Lazcano se compone de butacas, sillas, tumbonas, mesas de juego y de té, sofás, candeleros, burós, espejos y cabinets en japanning de color rojo escarlata ${ }^{[9]}$, decorados con motivos chinescos dorados y plateados con y sin relieve. En los asientos predomina la red o caña de Indias; las patas suelen ser de tipo cabriolé y se encuentran unidas entre sí mediante chambranas. Algunos muebles presentan la etiqueta comercial de Grendey y en determinados asientos esta se dispone sobre la parte interna de la red original de los mismos, lo que muestra su autenticidad. Las etiquetas localizadas hasta el momento son de dos clases. En la primera de ellas se lee: Giles Grendey. St John's Clerkenwell, London. Makes and sells all sorts of cabinet goods and glasses. El segundo tipo de etiqueta reza de esta manera: Giles Grendey. St John's Clerkenwell, London. Makes and sells all sorts of cabinet goods, chairs, tables, glasses (Gilbert 1978: 79, Jervis 1974: 1418, 1419, Ordóñez 2011:14). Asimismo, se han encontrado inscripciones con las iniciales de los nombres de algunos de los empleados de Grendey (Gilbert 1971: 544, 1986: 372), como también es el caso de las letras

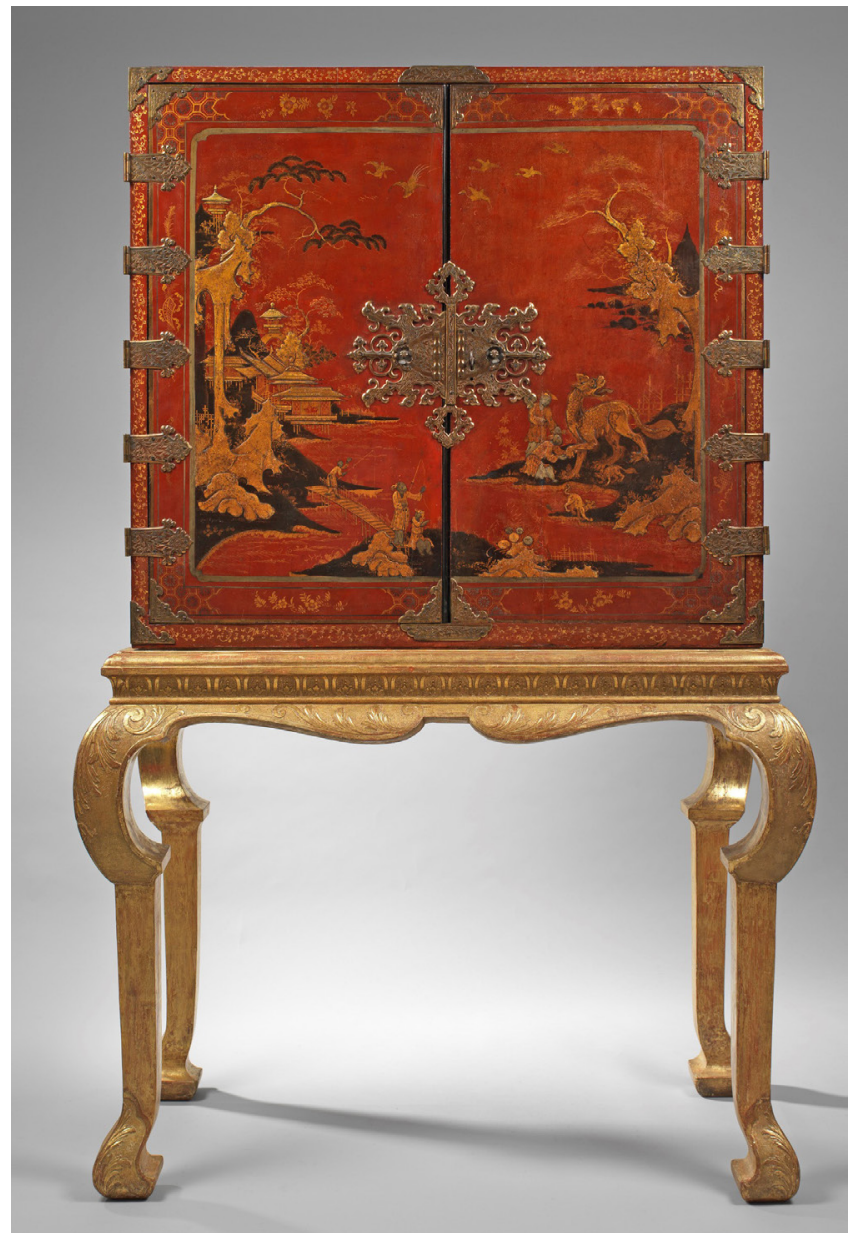

Figura 2.- Fotografía de otro cabinet de laca inglesa del siglo XVIII, de color rojo muy similar al andaluz, al igual que su ornamentación de laca roja con motivos chinescos. Encontrado en el mercado de antigüedades. Londres @Frank Partridge
$\mathrm{H} \mathrm{M}$, recientemente localizadas por nosotros en el interior del segundo cajón del cuerpo inferior de uno de los burós del Museo Nacional de Artes Decorativas.

Estas obras del lote de Lazcano, de excelente calidad técnica, tanto en lo que se refiere a su laca, como al trabajo de ebanistería, constituyen uno de los conjuntos que revisten mayor interés de la historia del mueble europeo. De ahí que sean numerosos los historiadores del mueble británicos de los siglos XX y XXI que se han referido a este. (Gilbert 1971: 544-550, 1996: 31; Huth 1972: 38, 39, Kisluk - Grosheide: 2006: 104, 105, Remington 1937: 209, 210 o Symonds 1935: $338,340,1941: 58,59,60$, etc. $)^{[10]}$.

El cabinet, objeto de nuestro estudio, podría haber pertenecido al mencionado lote, compuesto por más de setenta piezas de mobiliario realizadas por Grendey en la primera mitad del siglo XVIII para un noble español de la Casa de Valmediano o bien del Infantado ${ }^{[11]}$.

Durante nuestra investigación hemos podido comprobar que existe un cabinet en el comercio de antigüedades, muy similar a este, cuyo soporte ha sido atribuido al ebanista de la Casa Real británica James Moore (1670-1726), famoso por sus muebles tallados y dorados, principalmente mesas, candeleros y marcos de espejo, del que se adjunta una fotografía descargada de la página web que se indica en la nota $12^{[12]}$ [figura 2].

\section{Metodología. Materiales y Métodos.}

Uno de los planteamientos de nuestro estudio es el de comparar las características estilísticas y tecnológicas del cabinet localizado en España y la pareja de burós del MNAD, empleando como herramientas estudios directos, por una parte, y métodos de examen y técnicas de análisis por otro, como: microscopía óptica con luz visible, incidente y transmitida y también con iluminación ultravioleta (MO), cromatografía de gases-espectrometría de masas (GC-MS), microscopía electrónica de barrido asociada a un sistema de microanálisis por energía dispersiva de rayos $X$ (SEM- EDXS) y espectroscopia infrarroja por transformada de Fourier (FTIR ${ }^{[13]}$.

Para el examen técnico-científico se han utilizado micromuestras extraídas de los referidos muebles, con la elaboración de las correspondientes estratigrafías, incluidas en resina de metacrilato; a partir de las cuales procedimos a su observación con microscopía óptica (MO) para determinar la secuencia de capas que constituyen su revestimiento lacado; sobre ellas también realizamos microanálisis con microscopía electrónica de barrido (SEM-EDX) para el reconocimiento de los pigmentos y materiales de carga utilizados en su elaboración, así como su distribución y localización en los distintos estratos.

En cuanto a la identificación de los aglutinantes y otros materiales de naturaleza orgánica, se han empleado las técnicas de cromatografía de gases-espectrometría de 
masas (GC-MS) y espectroscopia infrarroja por transformada de Fourier (FTIR).

Los resultados obtenidos de la aplicación de estas metodologías instrumentales nos sirven para realizar un análisis comparativo, a nivel interno, de la técnica de la laca de las tres piezas en cuestión.

\section{Objetivos}

El objetivo principal de esta investigación es el de plantear la posible autoría de un cabinet de laca británica del siglo XVIII, conservado en una colección particular andaluza, al taller de Giles Grendey, tomando como premisas su posible pertenencia al "Lote de Lazcano" y otra serie de cuestiones que analizaremos a continuación, entre las que destaca su gran semejanza con los dos burós del Museo Nacional de Artes Decorativas de Madrid ${ }^{[14]}$, atribuidos a Grendey.

\section{Resultados y Discusión}

Atendiendo a la metodología descrita en el punto 2 de Materiales y Métodos planteamos este apartado de Resultados y Discusión describiendo, por una parte, los estudios derivados de la observación directa del cabinet y de los dos burós en cuestión, con el propósito de determinar y comparar las características estilísticas y tecnológicas de cada uno de ellos. Y por otra, los derivados de los análisis científicosy estratigráficos, con la finalidad de establecer la estructuración interna de la técnica de la laca de estas tres singulares piezas de mobiliario y verificar las analogías existentes entre ellas.

\section{—Estudios directos a partir de una observación visual exhaustiva.}

En este apartado especificamos en primer lugar las características constructivas y estilísticas del cabinet objeto de esta investigación, para continuar con las de los dos burós del Museo Nacional de Artes Decorativas.

\section{-El cabinet}

Este mueble ${ }^{[15]}$ fue construido con maderas de conífera, roble y haya. Cuenta con dos puertas al frente, cuya decoración es más fiel a la estética extremo oriental que la del resto de la pieza. Encierra un frente de diez gavetas, de distintos tamaños, distribuidas entre tabicas con molduras de doble caña [figura 3]. El interior de los cajones se decora con polvo dorado aplicado según el sistema de la venturina $^{[16]}$ (Ordóñez 2016: 365, 366, 367) sobre un estrato muy fino de laca negra. A simple vista, el frente anterior de las gualderas presenta una pintura muy similar a la empleada en la numeración dispuesta en las traseras y a la existente en los entrepaños correspondientes del frente de gavetas ${ }^{[17]}$. El mismo tipo de pintura reviste parte de los huecos de los cajones.

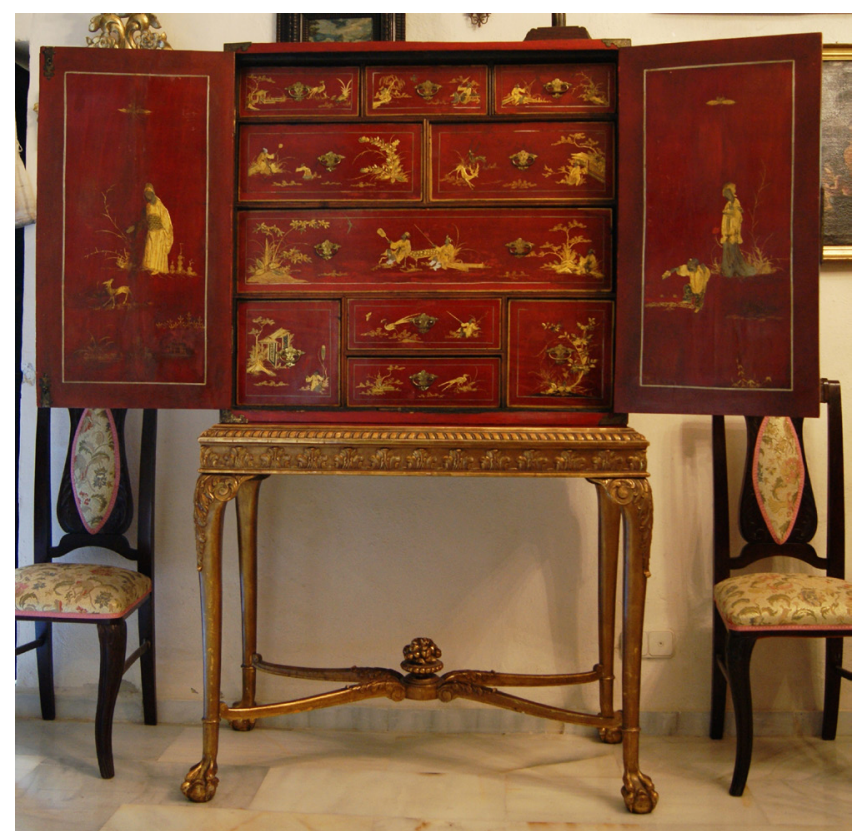

Figura 3.- Fotografía del cabinet de la colección andaluza que se muestra con las puertas abiertas, dejando apreciar la configuración interior constituida por diez gavetas de distintos tamaños distribuidas entre tabicas con molduras de doble caña, así como los personajes chinescos del interior de las puertas.

El cabinet apoya sobre una mesa de madera tallada y dorada con patas cabriolé y chambranas en forma de equis.

Se encuentra ornamentado con laca roja mostrando chinerías perfiladas de negro y bordeadas por cenefas lisas en dorado y plateado [figura 4]. La decoración externa de las puertas se enmarca en una orla con registros reticulares a base de polígonos entre motivos vegetales, dentro de los cuales se insertan pequeños círculos plateados.

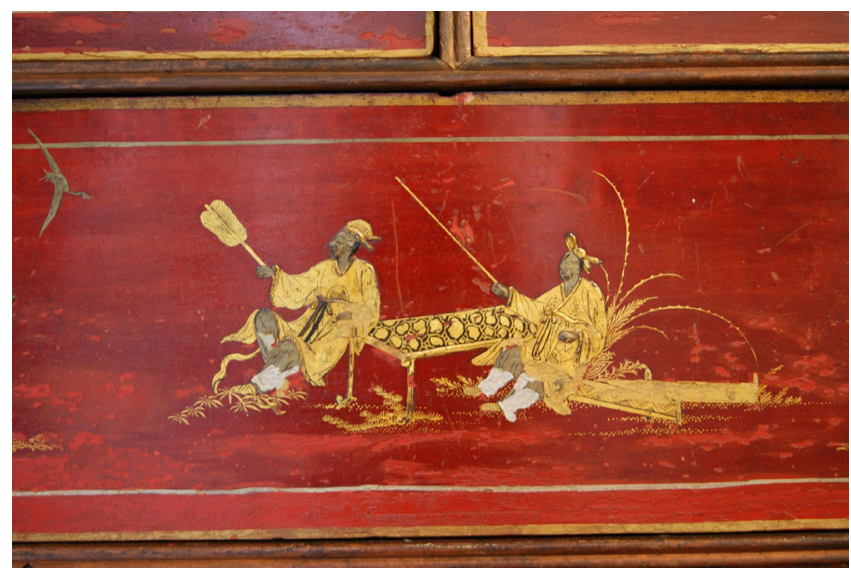

Figura 4.- Detalle de la ornamentación de uno de los cajones del cabinet, mostrando la decoración de chinerías perfiladas en negro y enmarcadas por cenefas lisas en dorado y plateado. 
Asimismo, presenta guarniciones de metal recortado y grabado, como es el caso de las cantoneras de los ángulos de las puertas y del armazón, los embellecedores del cierre de las mismas o los tiradores de asa de los cajones.

Fundamentamos la hipótesis de la atribución de la ejecución de este mueble al taller del artífice británico y al "Lote de Lazcano" teniendo en cuenta varios factores. En primer lugar, presenta características estilísticas y técnicas muy semejantes a las de otras piezas del lote, como son: la tonalidad rojo escarlata del fondo de la laca, la factura de las chinerías, las esencias leñosas empleadas, o el uso de reengrueso de madera bajo la laca. Por otro lado, se ha podido comprobar que existen notables semejanzas entre este cabinet y otro, atribuido al conjunto de Lazcano, en la actualidad de destino ignoto, cuya foto fue publicada por Symonds en 1935 [figura 5]. (Symonds 1935: 336, 340, Ordóñez 2011: 15, 16).

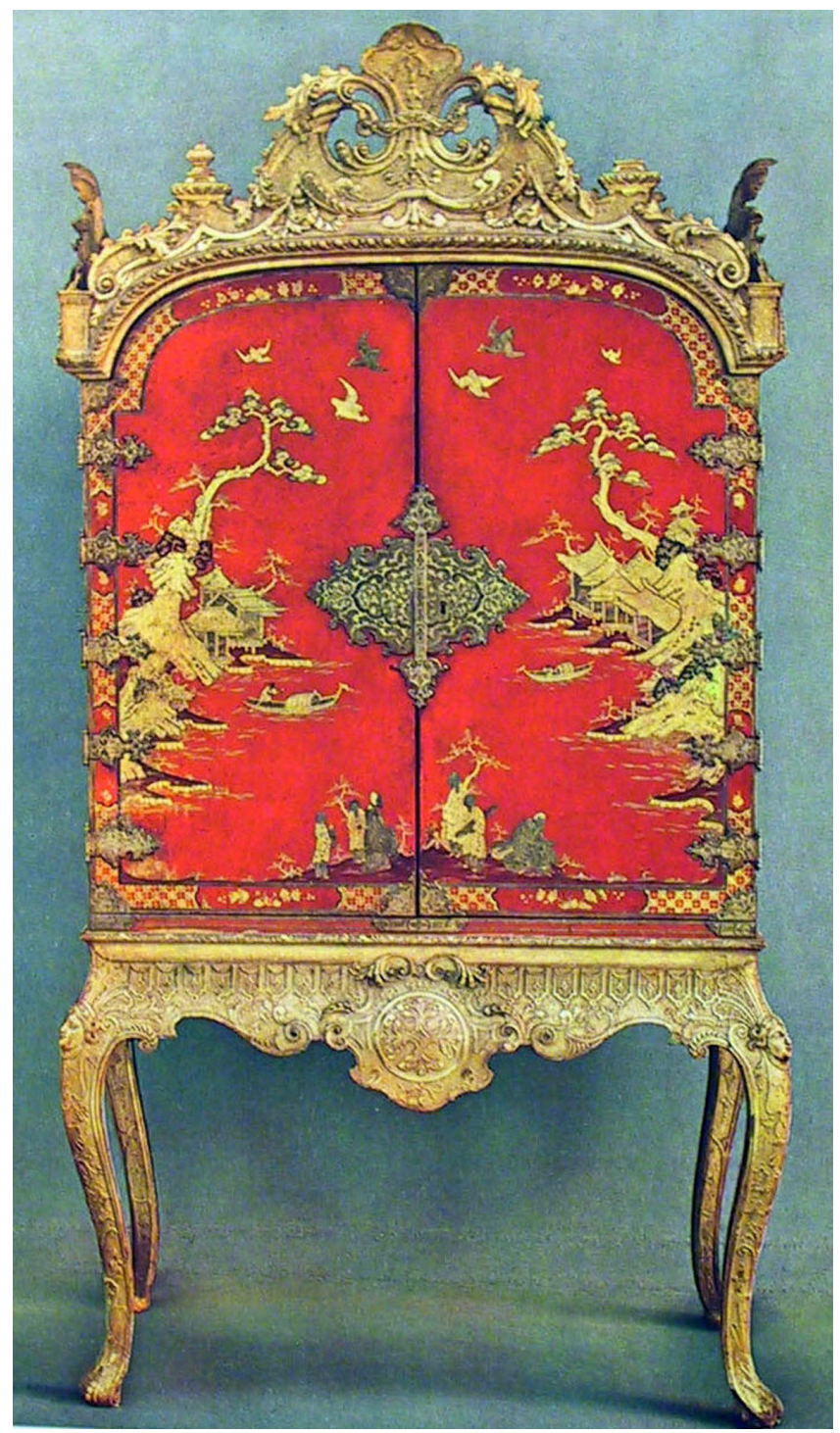

Figura 5.- Fotografía de un tercer cabinet, con destino desconocido, muy similar al estudiado, también atribuido al Lote de Lazcano, cuya foto fue publicada por Symonds en 1935.
Además, existe un detalle enormemente significativo como es que en el fondo de uno de los cajones ${ }^{[18]}$ se observa una inscripción de pintura color oscuro en la que reza: Henry ¿Mufiell, Mufeell o Mufsell? que podría corresponder al nombre y apellido de uno de los empleados de Grendey [figura 6]. Se trata de un dato relevante, puesto que, como hemos visto, en su taller era habitual que los ebanistas que trabajaban allí firmaran sus propias obras. Prueba de ello es que se han localizado asientos, con nombres propios o bien con las iniciales de los mismos, tanto en inscripciones a tinta o a lápiz como en estampillas o marcas realizadas a fuego. (Gilbert, 1971: 549), (Gilbert 1986: p. 372). Y entre ellos se encontrarían varias sillas del lote del palacio guipuzcoano (Gilbert 1996: 31, 248).

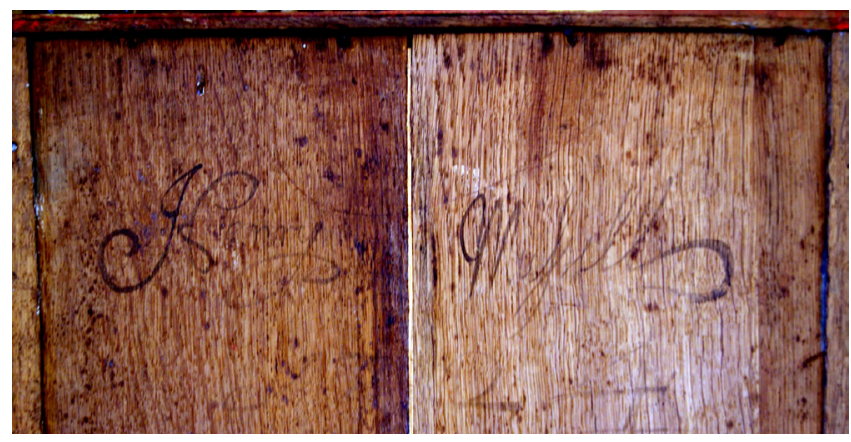

Figura 6.- Inscripción existente en el interior de uno de los cajones del cabinet andaluz, correspondiente probablemente al nombre de uno de los empleados del taller de Grendey, que podría tratarse del artífice que realizó este mueble, ya que era habitual en este taller londinense que los ebanistas que trabajaban allí firmaran sus propias obras.

Como hemos dicho, otra de las cuestiones que nos permiten atribuir este cabinet al conjunto de Lazcano lo constituye su semejanza con una pareja de burós del Museo Nacional de Artes Decorativas de Madrid, que formó parte con total seguridad del mismo, entre otras cosas porque aparecen en la foto mencionada de la "sala de las lacas" (Ordóñez 2016: 277, 515, 516, 517) [figura 7].

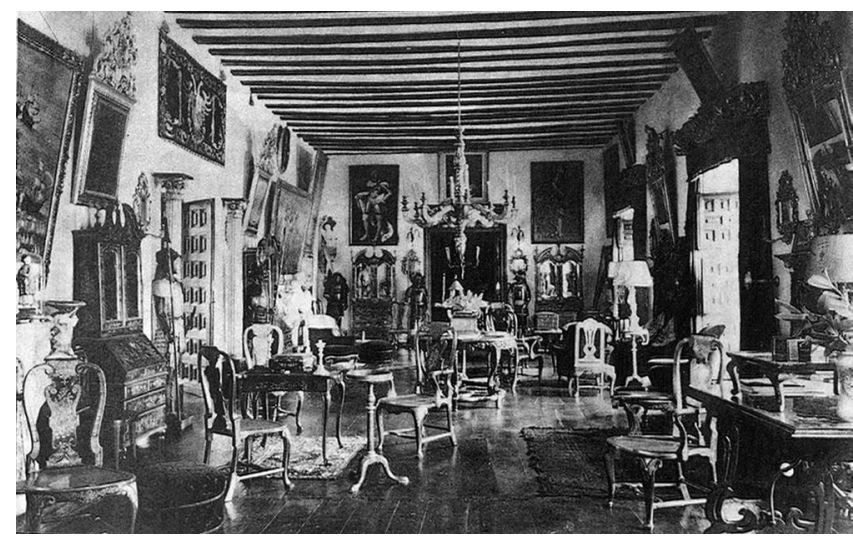

Figura 7.- Fotografía antigua, posiblemente de finales del siglo XIX o de inicios del XX, de la "sala de las lacas" del palacio de Lazcano (Guipúzcoa). Al fondo se pueden ver dos burós que, consideramos podrían tratarse, casi con total seguridad, de los exhibidos actualmente en el MNAD. 
Además, tal y como hemos indicado anteriormente, en el interior del segundo cajón del cuerpo inferior de uno de

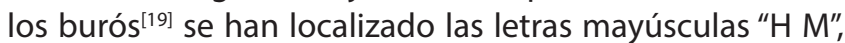
que casualmente se corresponden con las mismas iniciales del nombre propio completo que figura en el cabinet. Cuestión que se tratará más adelante.

Por estas razones consideramos oportuno incorporar en este trabajo una descripción estilística de estos dos burós para realizar un estudio comparativo con el cabinet, objeto de estudio.

-Los dos burós del Museo Nacional de Artes Decorativas (MNAD)

Estos dos muebles ${ }^{[20]}$ tienen una organización idéntica entre ellos, aunque difieren en algunos de los motivos decorativos.

Estructuralmente cada buró consta de dos cuerpos, el superior remata en un copete curvado coronado por pináculos dorados de madera torneada y presenta dos puertas con espejos que, al abrirse descubren diez gavetas de diferentes tamaños entre tabicas con molduras de doble caña, con decoración de venturina sobre laca negra en su interior y tiradores metálicos de asa sobre embellecedores recortados y grabados. En la parte más baja de este cuerpo se insertan dos tablas corredizas con tiradores metálicos circulares, que probablemente servían para soportar candeleros. El cuerpo inferior se compone de tres cajones con tiradores de asa similares a los anteriormente descritos y bocallaves del mismo estilo. Sobre ellos se sitúa una escribanía que encierra un registro con ocho huecos y cuatro gavetas con tiradores circulares de metal dorado. La tapa de la escribanía simula al exterior un cajón y la parte interna se reviste parcialmente de terciopelo azul oscuro ${ }^{[21]}$. El mueble reposa sobre pies galbeados [figura 8].

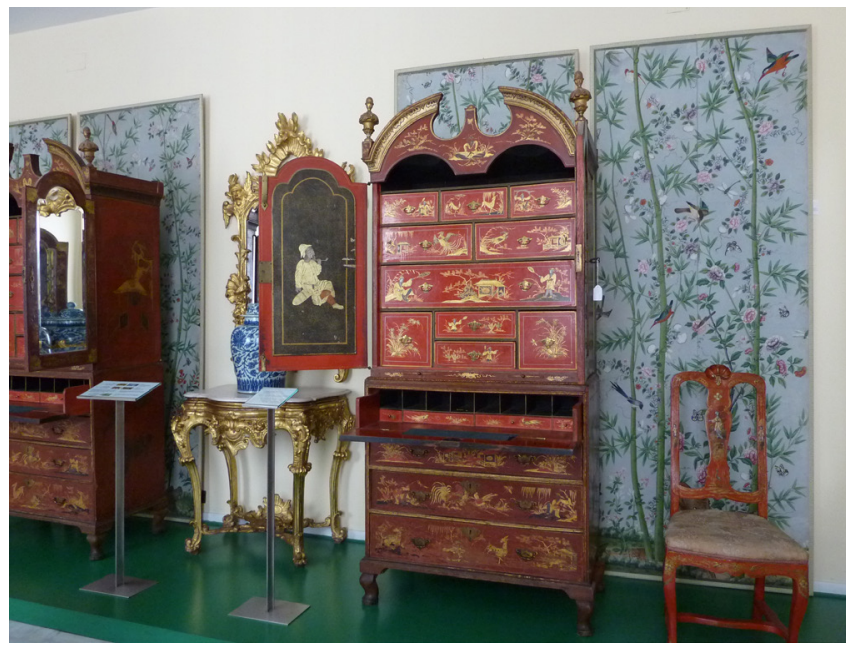

Figura 8.- Fotografía de los dos burós de Grendey, que formaron parte del lote de Lazcano, expuestos en la actualidad en el Museo Nacional de Artes Decorativas. $\odot$ MNAD
Estos dos burós presentan una laca de un color rojo, muy similar a la del cabinet, con motivos decorativos de escenas y ornamentos chinescos, dorados y plateados, que difieren entre un buró y otro. Sin embargo, en los interiores de las puertas se representan personajes idénticos en los dos casos: una figura masculina de rasgos y atuendo oriental, que fuma en pipa, sobre un fondo de laca negra con venturina dorada [figuras 9 y 10$]$.

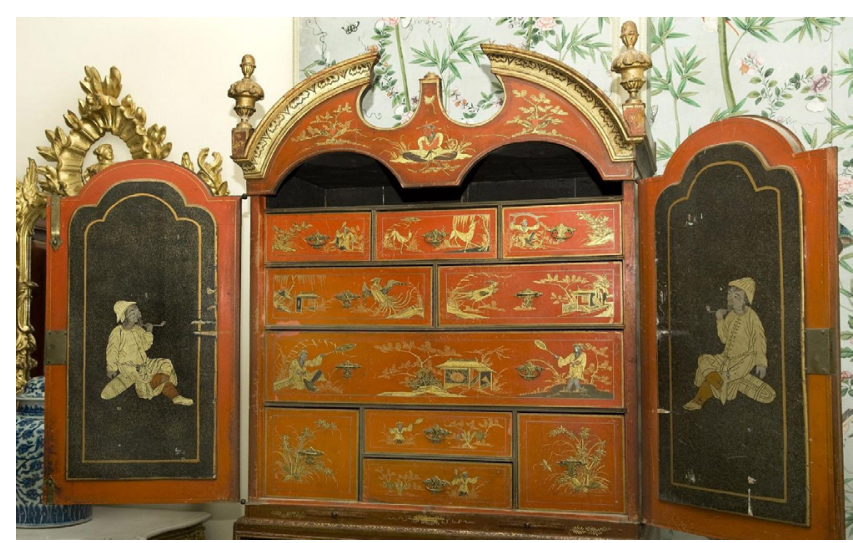

Figura 9.- Fotografía de la parte superior de uno de los burós del MNAD con las puertas abiertas, OMNAD, observándose en el interior de estas la decoración de chinerías constituida por dos personajes masculinos con rasgos y atuendo oriental, ejecutados sobre un fondo de laca negra con venturina dorada.

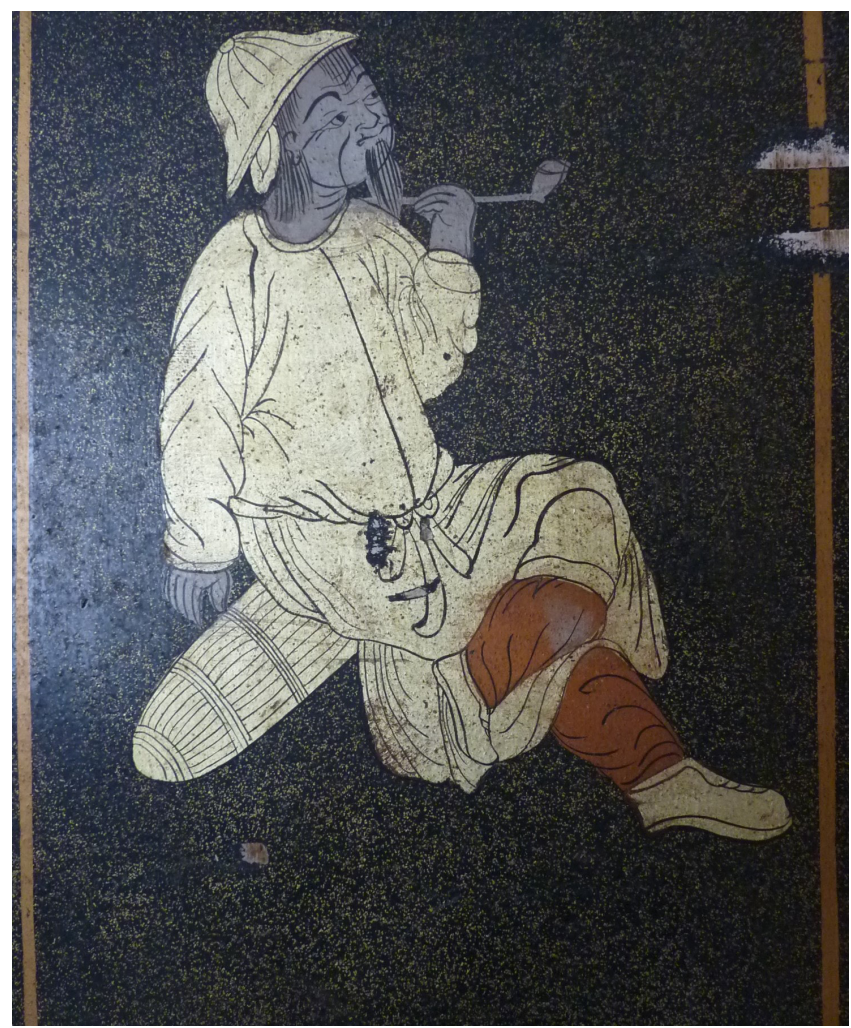

Figura 10.- Detalle del personaje oriental que decora el interior de la puerta izquierda de uno de los burós, OMNAD, en el que se aprecia la técnica de venturina dorada sobre el fondo de laca negra y el perfilado en negro de los detalles de la figura. 
Por su parte, como ya se ha mencionado, en el interior de uno de los burós figuran las iniciales $\mathrm{H}$ M realizadas a mano alzada con pincel, utilizando una pintura de color oscuro [Figura 11]. Otros signos de elaboración artesanal que consideramos merece la pena resaltar son una cruz de tono negruzco dibujada en la trasera externa de algunos cajones [22], quizá con el objetivo de señalar la cara de la tabla de madera que debía colocarse al exterior. La zona anterior de las gualderas de los cajones y parte de los huecos de los mismos se encuentran asimismo teñidas de negro. Por otro lado, todas las gavetas de estos dos muebles presentan una numeración arábiga realizada con tiza blanca e inscrita en un triángulo, aunque algunas de estas inscripciones se han borrado casi por completo.

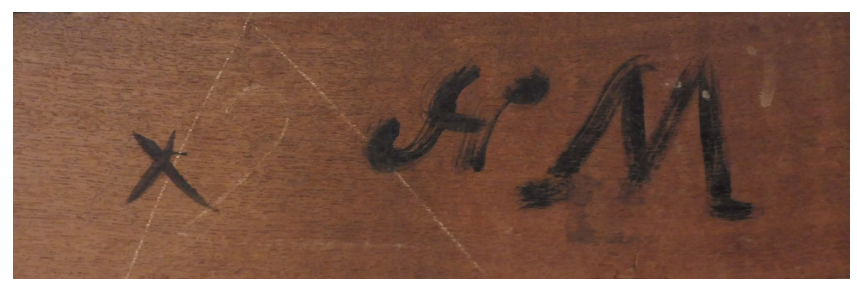

Figura 11.- Detalle de la inscripción con las letras mayúsculas $\mathrm{H} M$, localizada recientemente por nosotros en el interior del segundo cajón del cuerpo inferior de uno de los buros del MNAD ( $N^{\circ}$ Inv: 27482/2), que se corresponden con las mismas iniciales del nombre propio completo que figura en el cabinet andaluz: Henry ¿Mufiell, Mufeell o Mufsell?. @MNAD,

Los burós de laca británica de dos cuerpos, como los descritos, fueron muy apreciados en nuestro país. Muestra de ello son las numerosas referencias que se localizan en las fuentes escritas españolas de los siglos XVIII y XIX. Solían realizarse a pares para decorar una misma habitación atendiendo a las demandas de la nobleza (Gilbert, 1971: 549) y, a menudo se definían como papeleras (Ordóñez 2016: 277, 278), dado que las principales funciones que ejercían -contener papeles o documentos- eran similares a las de las antiguas papeleras o escritorios, vulgarmente conocidos como bargueños (Ordóñez 1984: 28, 29, 30. Rodríguez Bernis 2006: 161,162, 261, 262).

Casualmente, los siguientes anuncios de la prensa madrileña de la segunda mitad del siglo XVIII se refieren respectivamente a tres parejas de burós de dos cuerpos. En ellos se alude a su colorido, al número de cajones, a las puertas acristaladas, a los motivos dorados con relieve, a las guarniciones metálicas, etc:

...Se venden dos Papeleras, de dos cuerpos, compañeras, de última moda, hechas en Iglaterra (sic), dadas de charol, con el campo encarnado, y sus cristales correspondientes, y muy primorosamente trabajadas: daran razon del sugeto que las vende en la Prenderia que esta (sic), en la calle de Fuencarral, frente a la casa del Señor Marqués de Murillo... ${ }^{[23]}$

...En la carpintería de la calle de Fuencarral, frente de los Agonizantes, se venden dos Papeleras de dos cuerpos, hechas en Inglaterra, en el primer cuerpo tienen diferentes navetas, y en el segundo varios estantes dados de charol con figuras doradas de realce... ${ }^{[24]}$

...Se venden...Un par de Papeleras de charol encarnado, hechas en Inglaterra, con un herrage (sic), exquisito de bronce... ${ }^{[25]}$

\section{—Análisis científico de las lacas}

Constatadas las semejanzas estilísticas existentes en los tres muebles incluidos en este trabajo, planteamos realizar un estudio estratigráfico con el propósito de dilucidar otras coincidencias a nivel interno, relativas a la tecnología de elaboración de las lacas, basadas en las similitudes materiales y en la secuencia y correlación de las distintas capas constituyentes, características del procedimiento técnico de ejecución del lacado como recubrimiento decorativo. Todo ello con la finalidad de obtener datos científicos que pudieran sustentar y reforzar la atribución de este cabinet al taller de Grendey y su pertenencia al referido lote del palacio vasco de Lazcano.

En el caso del cabinet, la observación microscópica y el microanálisis de la estratigrafía preparada a partir de una micromuestra extraída de la cenefa plateada de un cajón, revela la presencia de un estrato rojo compuesto a base de bermellón, en el que se han detectado también incorporadas partículas de sílice. A continuación, existe una capa de color pardo rojizo elaborada con aceite de lino, que se visualiza aplicado en dos estratos, y también resina de colofonia, en baja proporción. Sobre esta capa parda se aprecia un estrato compuesto por laminillas de estaño. Superficialmente se encuentra otro elaborado con una mezcla de resina terpénica de tipo almáciga mezclada con aceite secante [Figura 12].

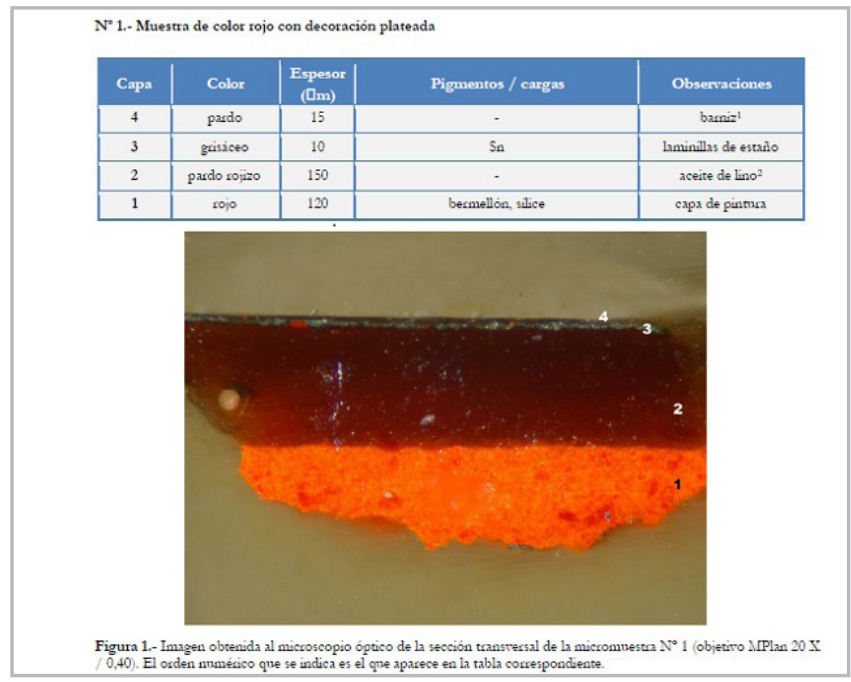

Figura 12.- Imagen obtenida al microscopio óptico de la sección transversal elaborada a partir de la micromuestra tomada de una cenefa plateada existente en el revestimiento lacado del cabinet andaluz. En ella se aprecia la secuencia de las distintas capas que constituyen el proceso de elaboración del revestimiento lacado de la ornamentación del japanning con el que fue decorado este mueble. 
En cuanto a los dos burós, se han analizado dos micromuestras (I y II) (Ordóñez 2016: 515-517.)

El estudio científico de la micromuestra (I), tomada de la cenefa plateada del lateral izquierdo del cuerpo inferior del buró, microscópicamente muestra una primera capa pictórica de tono rojizo, elaborada con bermellón aglutinado con aceite de lino. A continuación se extiende un estrato de color pardo oscuro compuesto principalmente por resina de colofonia. Sobre este encontramos una capa consistente en una lámina de estaño. Por último, superficialmente se percibe un estrato pardo de resina terpénica de tipo almáciga [Figura 13].

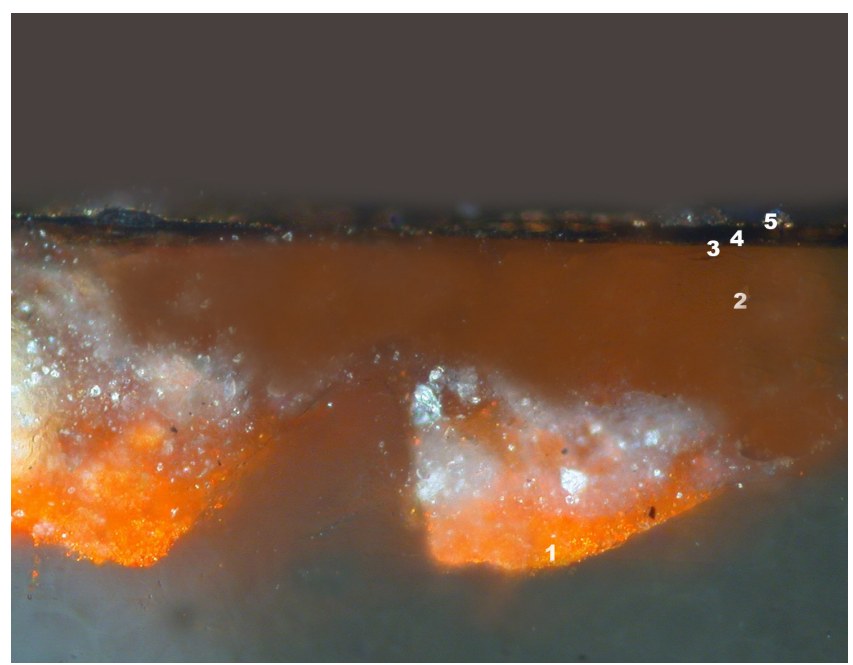

Figura 13.- Foto obtenida al microscopio óptico de la sección transversal elaborada a partir de una micromuestra tomada de una cenefa plateada del revestimiento lacado de uno de los burós del MNAD. En ella se aprecia un procedimiento de elaboración del japanning muy similar al encontrado, a nivel interno, en el cabinet de colección particular andaluza.

Por otra parte, en la micromuestra (II), extraída de una cenefa plateada sobre dorado del mismo lateral, la observación microscópica y el microanálisis asociado señala la existencia de una primera capa de tonalidad rojiza elaborada con pigmento bermellón, aglutinado posiblemente con una mezcla de aceite secante y resina de colofonia. El segundo estrato está compuesto por una gruesa capa de barniz de color pardo ejecutada con resina de colofonia. A continuación se visualiza un estrato dorado conseguido a partir de varios panes de oro superpuestos, en cuya composición participa el oro puro en un $57,1 \%$ aleado con plata en un 42,9\%. Seguidamente existe una capa compuesta por carbón vegetal, cuya existencia podría deberse a la intencionalidad de delimitar con carboncillo la cenefa dorada antes de proceder a ejecutarla. Por último, se observa un estrato de pan de plata, posiblemente adherido con aceite y por tanto podría tratarse de un plateado al mixtión, que se encuentra muy deteriorado, como pone de manifiesto la presencia de azufre en el microanálisis efectuado sobre ella [Figura 14].

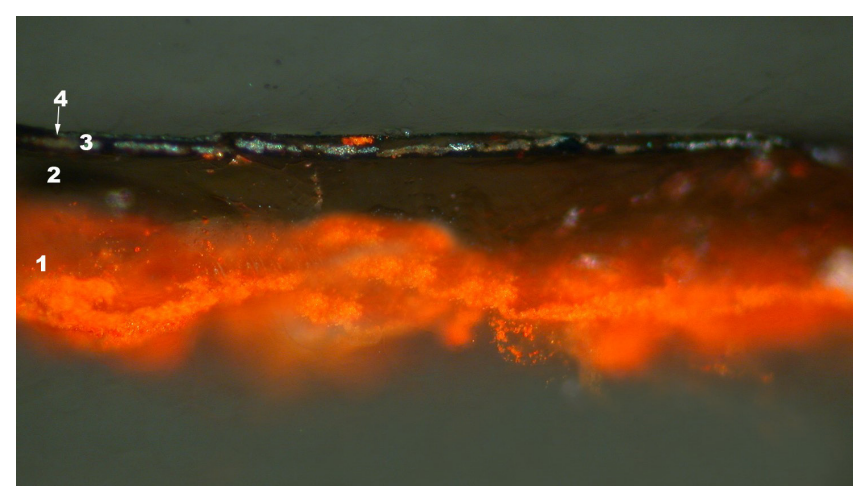

Figura 14.- Imagen observada con microscopía óptica de la sección transversal elaborada a partir de una micromuestra tomada de una cenefa plateada sobre dorado, que forma parte de la decoración del revestimiento lacado de uno de los burós del MNAD, en la que se muestra una configuración interna muy similar a las existentes en las dos estratigrafías anteriores.

\section{-Reflexiones}

Teniendo en cuenta los datos científicos anteriormente expuestos, deducimos que existe una gran semejanza en cuanto a las técnicas empleadas para la confección de los revestimientos decorativos entre los tres ejemplares analizados. En todos los casos, el tono rojizo del fondo del lacado se consigue fundamentalmente con bermellón ${ }^{[26]}$. Por otra parte, en las muestras no se aprecia la presencia de preparación, esto podría deberse tanto a que dicha capa no se hubiera alcanzado al extraer las correspondientes micromuestras de los muebles, como a que no existiera en la zona de donde se tomaron. Por eso, a pesar de que la ausencia de preparación no es inusual en el japanning ${ }^{[27]}$, no se pueda afirmar que toda la laca de los objetos examinados carezca de ella. De hecho, en estos casos, se ha constatado, a simple vista, su existencia en determinadas lagunas.

En tercer lugar, todas las láminas metálicas de las cenefas tanto en el cabinet como en los burós se adhieren al soporte mediante resina de colofonia ${ }^{[28]}$, aunque en el primer mueble se aprecia aceite de lino en mayor medida. Por su parte, las cenefas plateadas se ejecutan con pan de estaño. Finalmente, el barniz que aparece en la última capa de la micromuestra del cabinet y en la de la micromuestra I del buró se compone de resina terpénica. Sin embargo, en la micromuestra ॥ del buró no aparece barniz, quizá este no existe en la zona de donde se extrajo la muestra debido a alguna limpieza desafortunada llevada a cabo como remedio casero o también como consecuencia de algún proceso de reparación no profesional de la obra. Los resultados de estos estudios científicos han podido cotejarse con los realizados en el año 2007 en una tumbona de Grendey del National Gallery Victoria de Melbourne (Australia). De dicho análisis destaca la inexistencia de preparación de la muestra analizada y el uso del bermellón para conseguir el color rojo del fondo de laca (Ordóñez 2011: 18, 19. Dundosmore 2007: 69, 70). Por otro lado, también hemos analizado un candelero igual a otros del lote británico de Lazcano, de propiedad particular, del cual por el momento desconocemos si es original o si se trata de 
una copia. Los resultados del estudio se exponen en Ordóñez 2016: 521, 522, 523.

\section{Conclusiones}

Gracias a la información aportada por los estudios realizados, se han podido advertir numerosas coincidencias estilísticas y tecnológicas entre los tres muebles.

Estas coincidencias las clasificamos en función del color de la laca, las maderas utilizadas, la existencia de madera reengruesada bajo el revestimiento lacado, en la conformación de el frente de gavetas, en los motivos decorativos o en el estilo de los tiradores de metal dorado. Por otra parte, también existen coincidencias en determinadas marcas y detalles de la elaboración artesanal localizados en el interior de los muebles.

En lo que se refiere al colorido predomina en los tres casos el rojizo- "escarlata" del japanning. Otra coincidencia reside en las maderas utilizadas y su distribución en el mueble: pino y roble en el armazón, roble en los cajones y haya en la molduración. Asimismo se da la circunstancia que en zonas puntuales la laca se asienta sobre madera reengruesada ${ }^{[29]}$.

Además, el frente de gavetas de los tres muebles presenta idéntica configuración: cuatro registros horizontales en cada uno de los cuales se ubican de arriba abajo tres, dos, uno y cuatro cajones de distintos tamaños. Por su parte, las tabicas y entrepaños con dobles molduras de media caña son iguales en todos ellos ${ }^{[30]}$.

Por otro lado, la unión entre las gualderas y el frente de los cajones se ejecuta mediante delicados ensambles de cola de milano de trabajo muy similar en los tres muebles ${ }^{[31]}$.

En cuanto a la decoración, existe una gran semejanza entre la factura de las chinerías, la composición de las escenas, las actitudes de los personajes que se desenvuelven en ellas, la flora y la fauna representada, principalmente en los cajones de los tres muebles. También son similares las cenefas lisas -doradas en el exteriory plateadas en el interior-que enmarcan los motivos decorativos de los cajones, así como la decoración de venturina sobre laca negra del interior de los mismos.

Asimismo, responden a un mismo estilo los tiradores de metal dorado en forma de asa sobre embellecedor recortado y grabado de los cajones, asemejándose particularmente los del cabinet a los del cuerpo superior de los burós.

Por su parte, a simple vista, la pintura negruzca de los interiores del cabinet y de los burós es parecida en los tres casos. Y la factura caligráfica de los números de los cajones del primer mueble y la de las cruces e inscripción HM de los burós se asemeja considerablemente.

Igualmente existen grandes similitudes en el proceso interno de elaboración de las lacas de los tres muebles en cuestión, como se ha puesto de manifiesto a partir de los estudios estratigráficos y analíticos realizados sobre las secciones transversales de las micromuestras extraídas de los correspondientes lacados, tal como se describe en el apartado del análisis científico de las lacas.

Por último, podemos constatar que los materiales y métodos de elaboración de los revestimientos lacados responden en buena medida a la técnica de la laca europea del siglo XVIII, mediante la cual se conseguían, a base de meticulosos procedimientos, complejas estructuras estratigráficas con la intención de imitar el brillo, la transparencia y la profundidad de las lacas orientales ${ }^{[32]}$.

En cuanto a los motivos decorativos, exquisitos en los tres casos, son bastante fieles a los modelos extremo orientales, tal y como suele darse en el japanning que se producía durante la primera mitad de la centuria mencionada.

Los datos expuestos refuerzan la hipótesis de que nos encontramos ante un excepcional cabinet de gran valor histórico-artístico elaborado en el taller de Giles Grendey, perteneciente, como los burós del Museo Nacional de Artes Decorativas, al "Lote de Lazcano". Además, es posible que en la construcción de los tres muebles hubiera participado activamente el mismo empleado del artífice londinense, que responde a las letras mayúsculas $\mathrm{HM}$ en el caso de los dos buros del Museo de Artes Decorativas. Iniciales que coinciden con las del nombre completo que aparece en el cabinet objeto de nuestro estudio: Henry ¿Mufiell, Mufeell o Mufsell?

\section{Notas}

[1] Los cabinets son el equivalente europeo de los escritorios, contadores o papeleras (términos empleados en la documentación histórica) españoles, conocidos vulgarmente en la actualidad como bargueños. Adoptan forma de caja con cajones pequeños, también denominados gavetas, en su interior y se cierran normalmente con dos puertas. Servían para el almacenamiento y exhibición de objetos menudos, cartas, documentos, etc. Véase RODRÍGUEZ BERNIS 2006: $73,161,162,261,262$.

[2] Hemos preferido denominar este conjunto de muebles "Lote de Lazcano", en lugar de "Lote del Infantado" (Infantado Suite), tal y como lo define la historiografía británica, por el hecho de que, en el actual momento de la investigación, no existe certeza de que hubiera sido adquirido realmente por la Casa del Infantado.

[3] La laca europea consiste en una técnica decorativa, muyempleada en el mobiliario, que se difundió por Europa desde el siglo XVII surgida con la intención de imitar las lacas asiáticas, principalmente aquellas extremo orientales, pero mediante métodos europeos. Con ella se conseguían obras con características propias de cada país. La producción inglesa, a menudo denominada japaninng, por ser la laca japonesa la más valorada entre los lacadores británicos, se encontraba entre las de mayor calidad.

[4] Es de destacar, en este sentido, el inventario de bienes de Isabel 
de Farnesio de 1746 por el elevado número de artículos de laca inglesa que recoge. Ordóñez 2016: 761- 770.

\section{[5] Véase ORDÓÑEZ 2011: 17, 18}

[6] Sobre la biografía de este artesano consúltese Gilbert 1986: 371 , 372; 1996: 31, 32; Symonds 1935: 337, 338; 1941: 59, 60; https:// bifmo.data.history.ac.uk/entry/grendey-giles-1693-1780 British and Irish Furniture Makers Online

[7] Posiblemente el responsable de la venta fuera el decimoséptimo duque del Infantado don Joaquín María de Arteaga - Lazcano y Echagüe Silva Bazán (1870-1947) quien por esas fechas vivía en el palacio. Ordóñez 2011:20, nota14

[8] Entre ellos el Museo Victoria \& Albert de Londres, el Metropolitan de Nueva York, el Caramoor de Katonah (Estado de Nueva York), el Temple Newsam de Leeds, (Gran Bretaña), la National Gallery de Londres), el Museo Victoria de Melbourne (Australia) o el Museo Nacional de Artes Decorativas de Madrid.

[9] Principal calificativo que utilizan los autores anglosajones cuando aluden al color de estos muebles, también emplean la expresión color de lacre.

\section{[10] Véase ORDÓÑEZ 2011: 15, 16, 17.}

[11] Siempre se ha dado por hecho que los muebles fueron adquiridos por el duque del Infantado para decorar su Palacio de Lazcano. La foto sin fecha mencionada de un salón del edificio, en el que se pueden apreciar varios muebles de Grendey, ha servido para establecer este argumento fácil de refutar. $Y$ es que el palacio no perteneció al ducado del Infantado hasta 1883, cuando un descendiente del Señorío de Lazcano, don Andrés Avelino de Arteaga y Silva de Carvajal (1833-1910), marqués de Valmediano, heredó este título nobiliario a la muerte sin descendencia del XV duque del Infantado, don Mariano Téllez Girón (1814-1882), asimismo XII duque de Osuna, cuya relación remota con los señores de Lazcano, por vía femenina, se remontaba al siglo XVI.

Conociendo esta circunstancia el lote pudo haber sido adquirido por los Arteaga, señores de Lazcano y, a partir de 1692 marqueses de Valmediano, para decorar el palacio guipuzcoano -quizá Juan Raimundo de Arteaga Lazcano (1677-1761)- o bien por los duques de Infantado. En concreto por el décimo duque del Infantado don Juan de Dios de Silva y Mendoza, (1672-1737), o de su sucesora: la XI duquesa del Infantado María Francisca Alfonsa de Silva Mendoza y Sandoval (1707-1770). Estas dos últimas posibilidades indicarían que el destino inicial de los muebles no fue Lazcano, sino otra residencia perteneciente al ducado del Infantado y que sólo pudieron haber llegado a este palacio a partir de 1883, momento en que se funden las dos Casas de Lazcano e Infantado. ORDÓÑEZ 2011: 14.

En opinión de ciertos historiadores consultados no parece probable que el lote hubiera pertenecido en origen a los duques del Infantado. Debió encargarse por los Arteaga y llegar al puerto de Bilbao que en el siglo XVIII mantenía un comercio fluido con Inglaterra. De hecho, a la muerte de don Mariano Téllez Girón a finales del siglo XIX se hizo almoneda de todos los bienes del
Ducado de Osuna y del Infantado. Al no existir constancia de que este mobiliario proceda de la misma consideran que lo lógico es suponerlo en poder del Señorío de Lazcano desde el momento de su compra en el siglo XVIII.

[12]http://www.frankpartridge.co.uk/collection/english-furniture/ an-early-18th-century-red-lacquer-cabinet/Para mayor información sobre la obra de Moore véase ORDÓÑEZ 2016: 334, 340, 381.

[13] Estos estudios de laboratorio se realizaron en la empresa Artelab.

[14] Los burós pertenecieron a los duques del Infantado y en el año 2009 fueron adquiridos por el museo ( $N^{\circ}$ Inv: 27482/1 y № Inv: 27482/2) http://ceres.mcu.es/pages/Viewer?accion=4\&AMuse o=MNAD\&Museo=MNAD\&Ninv=CE27482/2 http://ceres.mcu.es $/$ pages $/$ Viewer?accion $=4 \&$ AMuseo $=$ MNAD $\&$ Museo $=$ MNAD $\&$ Ninv $=$ CE27482/1

[15] Dimensiones (Alto, ancho, profundo). Cabinet: $92 \times 96,50 \times 50$ $\mathrm{cm}$. Soporte: $90 \times 104 \times 54 \mathrm{~cm}$.

[16] Dicha técnica se inspira en el método japonés nashiji, conseguido moteando una superficie lacada con polvos metálicos. La denominación venturina, se debe a la similitud que adquirían las zonas así tratadas con la piedra semipreciosa que recibe este nombre. El interior de todos los cajones: gualderas, trasera y fondo, presenta la misma decoración sobre un fondo negro.

[17] Los cajones $n^{\circ} 2$ y $n^{\circ} 3$ presentan numeración también en la superficie externa de los fondos. El cajón no 6 contiene un compartimento secreto en la parte final del mismo, conformado por una tabla dispuesta paralelamente a la del fondo, que se extiende entre la gualdera izquierda y la derecha.

[18] En concreto en el nº 5.

[19] En el № Inv: 27482/2 y, concretamente, en la trasera externa del cajón.

[20] Dimensiones (Alto, ancho, profundo) $241 \times 105 \times 51$.

[21] En los huecos de uno de los muebles (№ Inv: 27482/1) existen cuatro cuencos de papier maché lacado en rojo con motivos de hoja de parra y uvas realizados en pan de oro. Uno de los cuencos presenta en la parte externa de su base una etiqueta rota en la que solo se aprecia ...rid...pez...dades...57...Esto podía indicar que los cuencos fueron adquiridos en una tienda madrileña de la calle del Pez. En el interior de dichos cuencos se ubican unos platillos de baquelita con la inscripción: bakelite. Rentería que podría indicar su procedencia de la fábrica de Rentería (Guipúzcoa), fundada en 1914, denominada Niesen. Baquelite. También cuenta el mueble con una pequeña caja de madera que contienen numerosas molduras del mismo material de muy reducido tamaño. Desconocemos a qué se debe la presencia de esta caja en la obra.

[22] Las cruces aparecen en todos los cajones del buró № Inv: 27482/2 y en algunos del № Inv: 27482/1.

[23] Diario noticioso universal, 21 de Junio de 1760. 
[24] Diario noticioso, 10 de Marzo de 1758.

[25] Diario Noticioso Universal, 17 de Noviembre de 1764.

[26] Este pigmento, muy empleado en los fondos rojos de laca europea, viene recomendado, a menudo combinado con el minio, en numerosas recetas presentes en tratados de los siglos XVIII y XIX. ORDÓÑEZ 2016: 548, 660

[27] A veces se prescindía de este primer estrato, siguiendo los consejos de ciertos tratadistas como Dossie, por considerar que de este modo se obtenían superficies de mayor resistencia. DOSSIE 1758: 407,408 .

[28] La colofonia era una de las resinas más empleadas en la laca europea y la que aparece mayoritariamente en los análisis llevados a cabo en lacas europeas. Véase ORDÓÑEZ 2016: 550, 661.

[29] Este método fue asimismo empleado en otras piezas de Grendey. De este modo se conseguía un soporte, para los distintos estratos matéricos, más liso que la madera maciza, lo que incrementaba el brillo final de la superficie. SYMONDS 1935: 341.

[30] Las molduras de los dos burós presentan en la actualidad un color verde oscuro, mientras que en las del cabinet apenas quedan restos de una pintura cuya tonalidad es imperceptible.

[31] A la cuidadosa ejecución de los cajones de dos de los cabinets del "Lote de Lazcano" se refiere Symonds. SYMONDS 1935: 16.

[32] ORDÓÑEZ GODED 2016: 327- 339.

\section{Agradecimientos}

Expresamos nuestro más sincero agradecimiento a Félix de la Fuente, Francisco Lara, Sofía Rodríguez Bernis y Andrés Sánchez Ledesma por su colaboración.

\section{Bibliografía}

AGUILÓ, M. P. (2005). “Via Orientalis 1500-1900. La repercusión del Arte del Extremo Oriente en España en mobiliario y decoración" en El arte foráneo en España. Presencia e influencia. Madrid: Dpto. de Arte Diego Velázquez. Instituto de Historia. CSIC: 532, 533.

ARTEAGA, C. (1994). La casa del Infantado. Cabeza de Mendoza. s/e. Madrid: 433.

BOWETT, A. (2009). Early Georgian Furniture 1715-1740. Antique Collectors' Club: Woodbridge: 37, 205.

DOSSIE, R. (1758). The hand maid to the Arts. J. Nourse: Londres: 407, 408.

DUNSMORE, A. (2007). “The Giles Grendey Daybed in the National Gallery of Victoria". Proceeding of the Inaugural Australian Furnishing History Symposium.Greg Peters and Jun Kennedy: Canberra. Woodbridge: 69, 70.
GILBERT, C. (1971). "Furniture by Giles Grendey for the Spanish trade". The magazine. Antiques, vol. 99: 544- 550.

GILBERT, C. (1978). Furniture for Temple Newsam House and Lotherton Hall. A catalogue of the Leeds Collection. Vol. 1. Maney: Leeds y National Arts Collections Fund, Bradford):79

GILBERT, C. (1986). Dictionary of English Furniture Makers 16601840. Maney: Leeds: 371,372

GILBERT, C. (1996). Pictorial Dictionary of Marked London furniture (1700-1840). Maney: Leeds: 31, 32, 248.

HUTH, H. (1972). Laquer of the west. An history of a craft and an industry $1550-1950$. University of Chicago Press: Chicago: 38,39

JERVIS, S. (1974). Jervis, S., "A great Dealer in the Cabinet Way. Giles Grendey". Country life, 6: 1418, 1419

JUNQUERA, J. J. (1999). "Mobiliario" en Las Artes decorativas en España. Historia General del Arte, vol. 45. Summa Artis. Espasa Calpe: Madrid: 434

KISLUK -GROSHEIDE, D. (2006). Europe Funiture in the Metropolitan Museum of Art. Highlights of the Collection. The Metropolitan Museum of Art: Nueva York: 104, 105

ORDÓÑEZ, C. (1984). "Muebles de los siglos XVI y XVII en el Museo Municipal de Madrid". Villa de Madrid, 81: 28-30.

ORDÓÑEZ, C. (2011). "Japanning en España. Un lote de muebles color escarlata realizado por Giles Grendey". Revista de la Associació per a l'estudi del moble, 14: 14-19.

ORDÓÑEZ, C. (2016). “De lacas y charoles en España. Siglos XVIXIX". Tesis Doctoral. UCM: 258-266, 277, 278, 280, 365-367, 515$517,521-523,548,550,660,661,761-770$

ORDÓÑEZ, L. (2015). “Acabados y dorado del mobiliario. De la teoría a la práctica". Tesis Doctoral. UCM: 334, 340, 381

REMINGTON, P. (1937). "A Gift of Furniture by Giles Grendey” The Metropolitan Museum of Art Bulletin, vol. 32, 9: 209, 210

RODRÍGUEZ BERNIS, S. (2006). Diccionario de mobiliario. Ministerio de Cultura: Madrid: 73,161,162, 261, 262.

SYMONDS, R.W. (1935). "Giles Grendey and the Export Trade of English furniture to Spain". Apollo, vol. 22: 16, 336-342

SYMONDS, R.W. (1941). "English Eighteenth Century Furniture Exports to Spain and Portugal". The Burlington Magazine for Connoisseurs, vol. 78, 455: 58, 59, 60.

SYMONDS, R.W. (1986). Masterpieces of English furniture and clocks Studio Editions: Londres: 81 


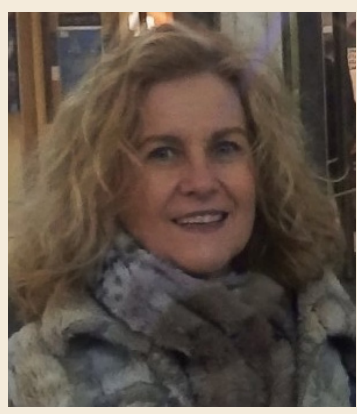

\section{Cristina Ordóñez Goded}

cristina@arcaz.com

Arcaz Restauración S.L

Doctora en Historia del Arte. Restauradora de Mobiliario. Socia fundadora de Arcaz Restauración S.L Investigadora independiente. Ha impartido clases y conferencias y dirigido Seminarios sobre la profesión en distintos Centros de Estudio y Universidades dentro y fuera de España. Es autora de diversas publicaciones relacionadas con la Conservación y las técnicas del mobiliario, tanto en medios nacionales como internacionales. En 2016 defendió su Tesis Doctoral titulada: De lacas y charoles en España: Siglos XVI-XIX (Premio extraordinario de doctorado. UCM)

\section{Luis Rodrigo Rodríguez Simón}

Irsimon@ugr.es

Facultad de Bellas Artes. Universidad de Granada.

Doctor en Bellas Artes. Profesor Titular de Restauración. Departamento de Pintura. Facultad de Bellas Artes. Universidad de Granada.

Su actividad investigadora está relacionada con el estudio de pinturas y obras de arte con radiaciones electromagnéticas (rayos X, reflectografía Infrarroja, UV, colorimetría), así como en el análisis de pigmentos (SEM-EDX) y aglutinantes (CGMS) e interpretaciones estratigráficas. Con la finalidad de investigar en las técnicas artísticas, procesos creativos y en la autentificación y atribución de pinturas y bienes culturales. 